\title{
Article \\ Studying Four Different Permanent Magnet Eddy Currents Heaters with Different Magnet Areas and Numbers to Produce Heat Directly from a Vertical Axis Wind Turbine
}

\author{
Ali Khanjari ${ }^{1}$, Sangkyun Kang ${ }^{1}$, Daeyong Lee ${ }^{2}$, Dae-Yi Jung ${ }^{3}$ and Jang-Ho Lee ${ }^{3, *}$ \\ 1 Department of Mechanical Engineering, Kunsan National University, Gunsan 54150, Korea; \\ ali.khanjari69@gmail.com (A.K.); whatgg@naver.com (S.K.) \\ 2 Institute of Offshore Wind Energy, Kunsan National University, Gunsan 54150, Korea; \\ daeyong.lee@kunsan.ac.kr \\ 3 School of Mechanical System Engineering, Kunsan National University, Gunsan 54150, Korea; \\ dyjung@kunsan.ac.kr \\ * Correspondence: jangho@kunsan.ac.kr
}

\section{check for}

updates

Citation: Khanjari, A.; Kang, S.; Lee, D.; Jung, D.-Y.; Lee, J.-H. Studying Four Different Permanent Magnet Eddy Currents Heaters with Different Magnet Areas and Numbers to Produce Heat Directly from a Vertical Axis Wind Turbine. Energies 2022, 15, 275. https:// doi.org/10.3390/en15010275

Academic Editors: Sukanta Roy and Ujjwal K. Saha

Received: 16 November 2021 Accepted: 24 December 2021 Published: 31 December 2021

Publisher's Note: MDPI stays neutral with regard to jurisdictional claims in published maps and institutional affiliations.

Copyright: (C) 2021 by the authors. Licensee MDPI, Basel, Switzerland. This article is an open access article distributed under the terms and conditions of the Creative Commons Attribution (CC BY) license (https:// creativecommons.org/licenses/by/ $4.0 /)$.

\begin{abstract}
Changing the magnetic field on a conductor metal can induce eddy currents, which cause heat generation. In this paper, we use this idea to convert wind energy into thermal energy directly. This system contains a vertical axis wind turbine and an eddy currents heat generator. The eddy currents heat generator has two parts. The first part is a rotor with some permanent magnets causing the magnetic field changes, and the second part is a stator that acts as a conductor. The magnetic field changes in the heat generator play an important role in power output; therefore, we test four different magnet arrangements with different pole numbers on the rotor at different rotational speeds from $100 \mathrm{rpm}$ to $500 \mathrm{rpm}$ to measure the input torque and power needed to rotate each model. Then, based on the measured data, the wind turbine is designed by Qblade software based on the blade element momentum theory. It is shown that compared to the weight of the heat generator and the area of magnetization, designing a proper magnet arrangement for the heat generator can change the output power considerably as it can trigger the magnetic field fluctuation along the direction of rotation. For example, opting for a proper arrangement on the rotor decreases the number of poles from 120 to 24 but increases the power input from $223 \mathrm{~W}$ to $1357 \mathrm{~W}$.
\end{abstract}

Keywords: wind energy; vertical axis wind turbine; eddy currents; permanent magnets; heater

\section{Introduction}

Demanding energy for the building sector accounts for more than $30 \%$ of the total world's energy consumption [1,2]. Moreover, more than half of this portion is used for space heating and cooling of the buildings, which require burning fossil fuels or electricity. In recent decades, renewable energy resources as an alternative to fossil fuels were developed widely to deal with environmental issues and energy market demand [3]. They are employed for different applications such as electricity generation, heating, and cooling. Of these different types of renewable energy resources, solar and wind power experienced considerable growth in producing energy in recent years [4]. Solar panels can capture heating energy from the sun directly. However, the procedure of producing heat from wind energy requires several steps; firstly, the kinetic energy of the wind flow is converted into electricity, and then heat energy is obtained by electric resistance heaters or heat pumps, which is an inefficient way to produce heat due to the energy loss in each step [5]. Therefore, if we can convert the wind energy into heat directly, not only will the inefficiencies decline, but also the final energy costs will decrease.

One idea to generate heat directly from wind energy is the eddy currents phenomenon [6]. Electrical eddy currents are closed paths of electrical current that are induced in a conductor 
moving in a magnetic field due to Faraday's law. These loops on the conductor can produce breaking torque and heat [7]. Even though this phenomenon in wind engineering is widely known as a negative phenomenon that raising the temperature of permanent magnet synchronous generators and inefficiencies, we want to employ the eddy currents phenomenon to just generate heat as the output power.

In this paper, a device called Permanent Magnet Eddy Current Heating (PMECH) with the different magnet areas coupled by a vertical axis wind turbine will be tested to produce heat from wind energy directly.

Regarding the Figure 1, by rotating the rotor upon which a various number of magnets were assembled, the magnetic field starts fluctuating on the stator. Then, the closed circles of eddy currents will be induced on the stator based on Faraday's law, which opposes the direction of the magnetic field on the rotor. Therefore, the induced eddy current loops will resist against the direction of motion of the rotor and generate heat: (heat is produced in accordance with the Joule-Lenz's Law and hysteresis losses) [8].

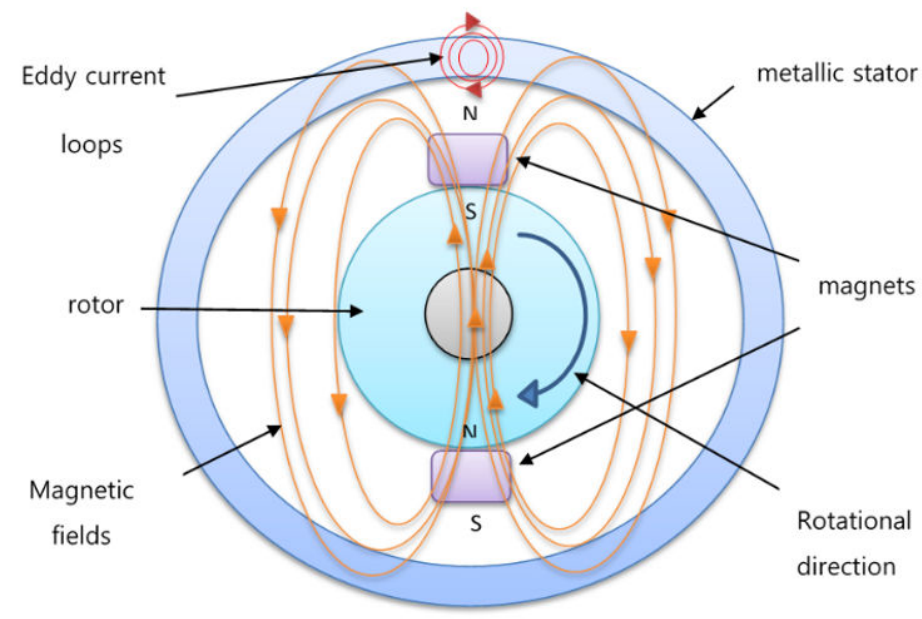

Figure 1. Eddy current principle [9].

The PMECH system of this study is compact and is intended to be utilized as a renewable thermal energy supplier device for farming facilities, fish farms, heating systems in mountainous areas, and anti-ice-freezing systems on iced roads. Compared with the conventional wind power generation system, there is a large cost difference depending on the installation conditions or specifications. Considering the structural aspect, as shown in Figure 2, the wind-heat system has the simplest building, consisting of a wind turbine, a heat source device, and a heat storage tank, while the conventional wind power system usually contains a wind turbine, an alternator, a controller, an inverter, power lines, and capacitors. On the other hand, the power control system in the wind turbine only takes about $30 \%$ of the total installation cost. However, since the power control system is replaced by a heat storage tank and a circulation pump, it is difficult to compare and review the installation cost, but the wind power generation system has a complicated structure, so the structure is maintained compared to the very simple wind-heat system.

Wind energy utilization in the industry became very prevalent in recent years [10]. It is widely used to generate electricity. On the other hand, by introducing permanent magnet synchronous generators in wind turbines, implementing them as an efficient way to produce electricity directly without presenting transmission systems has been popular [5]. However, the effects of the eddy currents phenomenon on the energy loss of alternators are a serious problem in designing steps [6]. Even though this phenomenon is known as a negative aspect of generating power in the wind industry, several studies were conducted to employ these power losses in different industries to produce heat by means of induction heaters or as a braking system in buses or trucks. We can also implement this idea to 
generate heat from renewable energy resources. However, there are few studies concerning this aspect $[7,8]$.

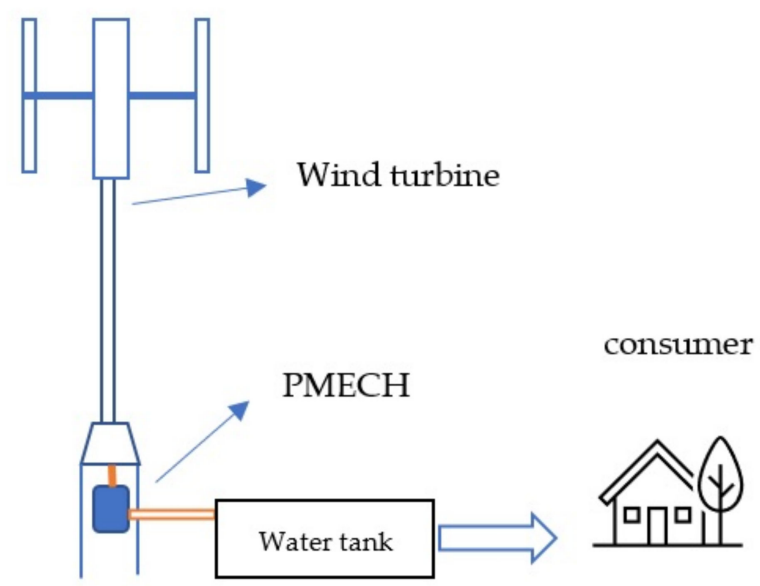

Figure 2. Diagram of the wind-heat system.

\section{Recent Studies}

Chakirov introduced the first idea to produce heat directly from wind energy based on the principle of the Joule machine coupled by a vertical axis wind turbine [11]. He used a water container containing an impeller. Wind energy rotates the impeller, and friction between water and the impeller surface raises the water temperature. Sobor tested a permanent magnet eddy currents heater at different rotational speeds and showed that compared to the Joule machine, the eddy currents heating device was much more efficient at low angular velocities [12]. However, at high rotational speeds, they have similar power coefficients. Moreover, it was calculated that the energy efficiency of the eddy currents heating device can exceed $90 \%$ of the water temperature. In another study, Worley tested a PMECH to measure the input torque in different rotational velocities [9]. He assembled the permanent magnets on a disc and tried to develop his analytical model to predict the input torque of the system at each rotational speed.

These studies show that PMECH systems can have a satisfactory power coefficient. Therefore, studying the parameters that can change the energy output has become popular among the engineers. Lieu proposed a system including a vertical axis wind turbine connected to a PMECH and studied the effect of air gaps between permanent magnets and the stator on the temperature changes at different rotational speeds. It was concluded that decreasing the air gap and increasing rotational speeds raise the output temperature [13].

Other numerical simulations based on the Finite Element Momentum (FEM) studied the effects of different parameters, namely: magnet numbers, air gaps, rotational speeds, the thickness of the conductor, and different metals as the conductor on PMECH performance to produce heat from wind energy [14-18].

While in all studies, there is just one rotor used to evaluate its performance in different conditions based on FEM methods, in this study, we want to experiment with four different PMECHs with different magnet arrangements, pole numbers, and magnet numbers at different rotational speeds to show the importance of the magnet arrangements on the performance of PMECH. Moreover, changing the pole and magnet numbers will result in changing the total weight of the heat generator; consequently, a portion of input power will be lost because of the mass, but it was neglected in previous studies. Therefore, to evaluate the effect of the pole number and magnet arrangement on the power performance, we will calculate the input torque per number of magnets used on the rotor, which is the main novelty of this study.

Then, based on the measured input torque and power, a vertical axis wind turbine will be designed. 


\section{Materials and Methods}

\subsection{PMECH Model}

A simple 3D sketch of the PMECH used in this research is shown in Figure 3 [19]. The material used as the conductor is aluminum. A specific type of the permanent magnet (Nd-Fe-B) with magnetic flux density $4000 \mathrm{G}$ is used to induce magnetic flux on the conductor [20-22]. The upper face of each magnet facing the inner conductor is the $\mathrm{N}$ pole, and another face is the $S$ pole.

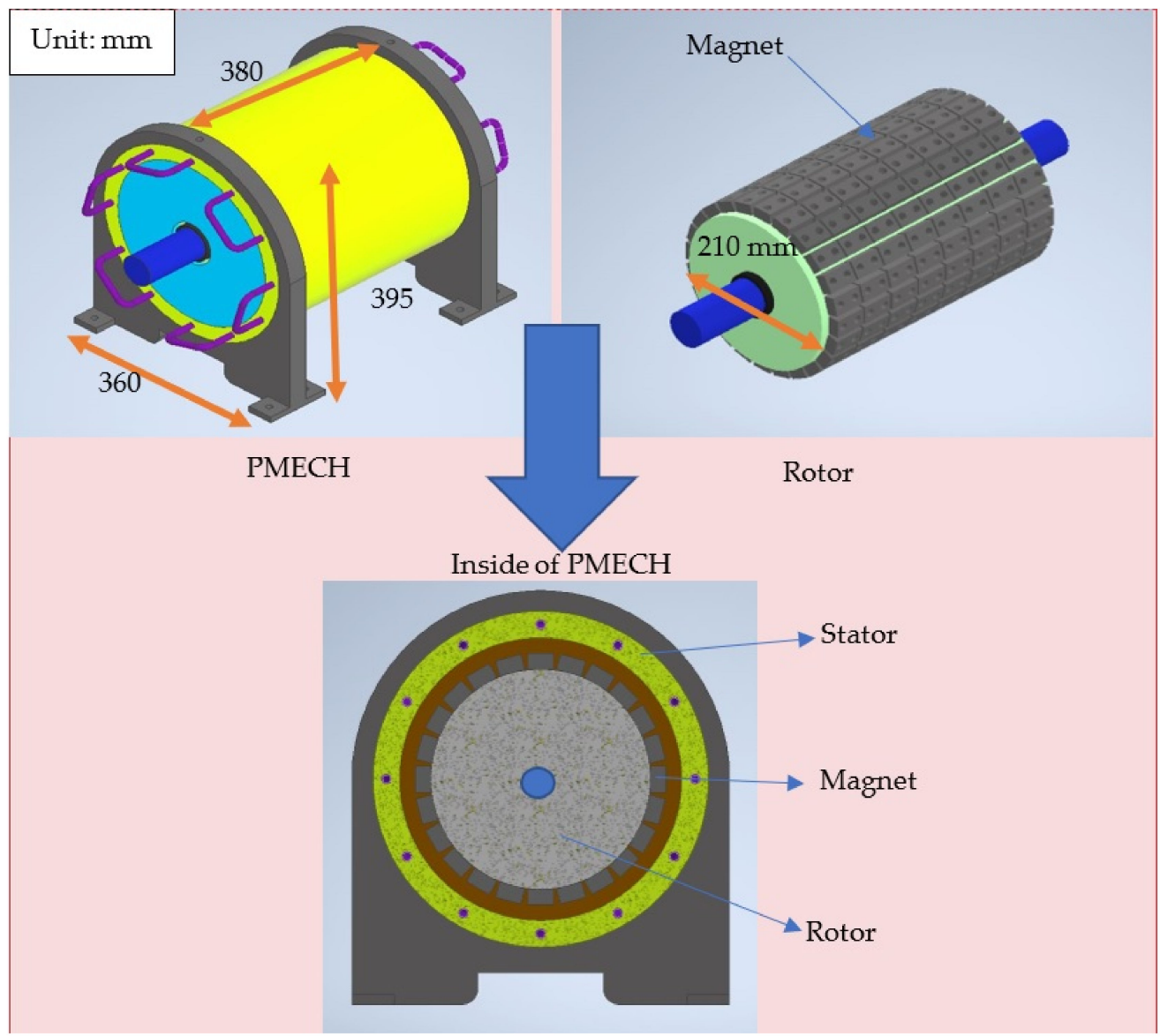

Figure 3. 3D prototype of PMECH.

When the cylindrical rotor rotates, a magnetic field will apply in the same direction as its axis; then, it will generate resistive torque, which is akin to the eddy current braking used for industrial machines, buses, and trains. However, it is important to recognize the distinction in the application for PMECH versus braking.

First, spinning the rotor establishes a changing magnetic field, which induces an electric field in the stator under the area of the magnet in accordance with Faraday's Law. The induced electric field then generates an eddy current. The induced current density is given by [23].

$$
j=\frac{E}{\rho}=\frac{B v}{\rho}=\frac{B R \omega}{\rho}
$$

where $j$ is the current density $\left(A / m^{2}\right) ; E$ is the electric field $(V / m) ; \rho$ is the resistivity of the stator (Ohm-m); $B$ is the magnetic field strength (Tesla); $v$ is the velocity of the magnet $(\mathrm{m} / \mathrm{s})$; $R$ is the distance from the center of the rotor to the center of the magnet pole $(m) ; \omega$ is the 
angular velocity of the disk ( $\mathrm{rad} / \mathrm{s})$; and $\sigma$ is the conductivity of the stator (Siemens $/ \mathrm{m}$ ). The power dissipated per unit volume by the eddy currents through Ohmic heating is given:

$$
P_{h g}=j^{2} \rho=\frac{(B R \omega)^{2}}{\rho}
$$

where $P_{d}$ is the power dissipated per unit volume $\left(\mathrm{W} / \mathrm{m}^{3}\right)$. In this study, the magnetic field is the most important parameter for us as the main cause of the eddy current induction.

According to Equation (2), power generation is proportional to $\frac{(B R \omega)^{2}}{\rho}$. Therefore, some approaches can be adopted to change the input torque, such as the area of magnetization, creating a high frequency alternating electromagnetic field to produce a powerful magnetic induction, improving the conductivity of metal. In this study, we want to create a high frequency alternating electromagnetic field by changing the position of the magnet on the rotor as it has the highest effect on induction. Compared to other variables which may increase the size and cost of the eddy current generator, finding the proper magnet arrangement not only can reduce the area of magnetization but also rotational speed.

\subsection{Experiment}

The experimental setup of the PMECH is shown in Figure 4. To control the rotational speed of the AC motor, a power supply unit is used. The measuring equipment contains a computer monitoring real-time data and the data logger measuring torque, rotational speed. The specifications of the measurement equipment are indicated in Table 1. Moreover, all output data such as angular velocity and torque will be stored in a data logger.

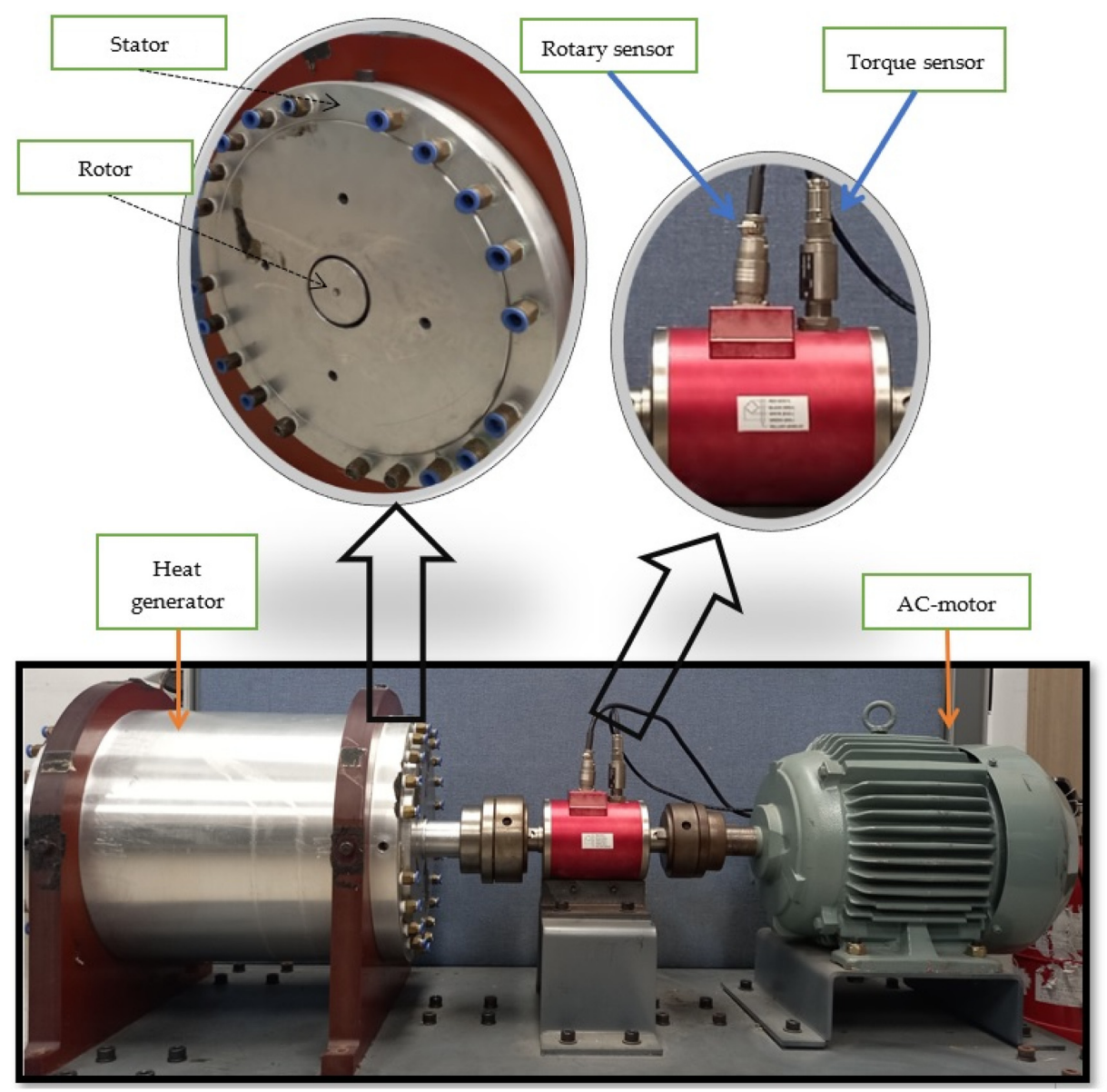

Figure 4. PMECH Test setup. 
Table 1. Specifications and accuracies of measurements.

\begin{tabular}{cc}
\hline Item & Characteristics and Accuracy \\
\hline Torque sensor & $0.23-0.87 \%$ \\
\hline Rotary sensor & $\pm 0.031 \mathrm{rad} / \mathrm{s}$ \\
\hline Computer monitor & $\begin{array}{c}\text { Data storage and real-time } \\
\text { monitoring }\end{array}$ \\
\hline
\end{tabular}

Regarding Figure 5, there are four rotors with different magnet numbers and magnet areas. Two $Z$ and $\theta$ vectors are introduced to show the direction of the magnet rows on the rotor. Case 1 covered with 120 permanent magnets and 48 poles in the $\theta$ direction; case 2 with 32 permanent magnets and 16 poles in the $\theta$ direction has 40 and $50 \mathrm{~mm}$ gaps between each magnet in the $Z$ and $\theta$ directions, respectively; case 3 with 24 permanent magnets and 12 poles in the $\theta$ direction is an array with 40 gaps between magnets in the $Z$ direction and a fixed $75 \mathrm{~mm}$ gap between magnets in the $\theta$ direction; and case 4 has 48 magnets and 24 poles [24].

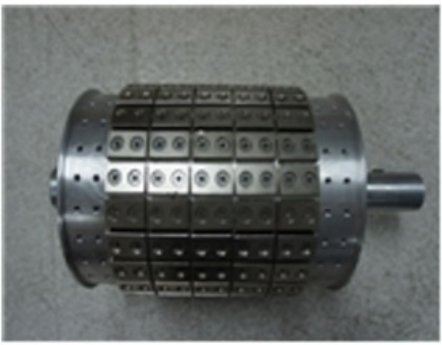

Case 1 (120 magnets \&

48 poles)

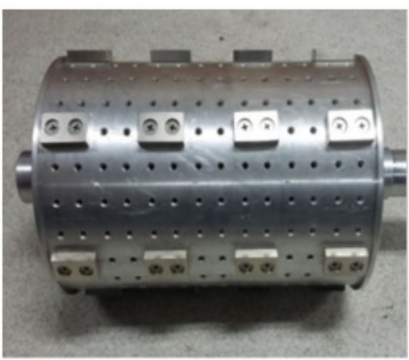

Case 3 (24 magnets \& 12

poles)

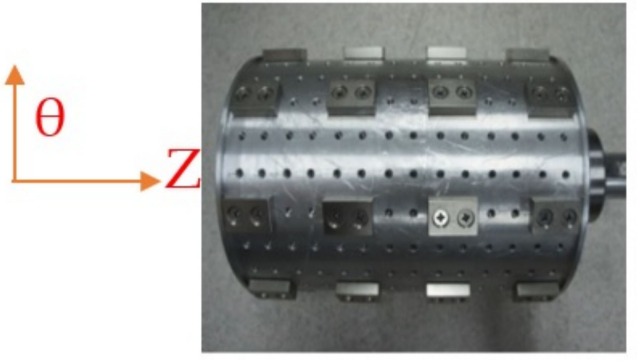

Case 2 (32magnets \& 16

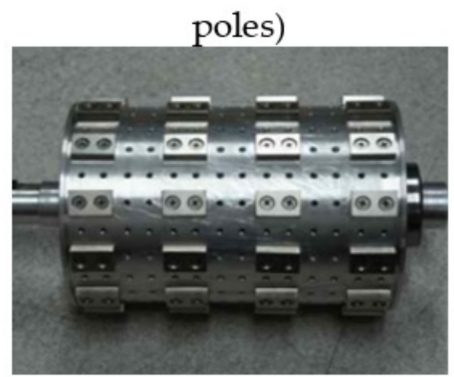

Case 4 (48 magnets \& 24

poles)

Figure 5. Four different rotors with different magnet areas.

Uncertainty analysis is important to improve the reliability of experimental results, as well as during the planning stage. The uncertainty value (U) corresponds to $90 \%$ or $99 \%$ confidence that the true value exists between $\pm \mathrm{U}$, based on the measurement results. Our uncertainty analysis was based on the method of the American Institute of Aeronautics and Astronautics in which error is classified as precision or bias error. The root sum square method was used to determine the uncertainty of the measured values.

A coverage factor of $k=2$ provides a confidence level of about $95 \%$ [25].

The uncertainty in the power input $(\mathrm{P})$ is given by Equation (1):

$$
\frac{U_{P}}{P}=\left[\left(\frac{\partial P}{\partial T} \frac{U_{T}}{P}\right)^{2}+\left(\frac{\partial P}{\partial \omega} \frac{U_{\omega}}{P}\right)^{2}\right]^{0.5}
$$


Partial differentiation of Equation (3) results in the following:

$$
\frac{U_{P}}{P}=\left[\left(\frac{U_{T}}{\partial T}\right)^{2}+\left(\frac{U_{\omega}}{\partial \omega}\right)^{2}\right]^{0.5}
$$

\subsection{Wind Turbine Modeling}

To model the vertical axis wind turbine, an open-source software called Qblade, modeling wind turbines based on the blade element momentum theory, is employed [26].

Qblade can model both vertical and horizontal axis wind turbines. To model a wind turbine in Qblade, some input data such as airfoil type, chord length of the airfoils, rotor diameter, blade length, Reynolds number, lift and drag coefficient of airfoils versus angle of attack, and wind speed range are needed to define. Then, Qblade divides the blade into several small elements and starts calculating the aerodynamic loads of each section based on the Blade Element Momentum theory. The principle of employing Blade Element Momentum theory is introduced in Section 2.4. Finally, the output power of the wind turbine can be plotted versus different wind speeds and rotational speeds.

As shown in Table 2, the vertical axis wind turbine reviewed in this paper is a threebladed H-Darrius type, with a diameter of $2.2 \mathrm{~m}$, the blade height of $3.2 \mathrm{~m}$, and chord length of $0.3 \mathrm{~m}$, and starting wind speed of $3 \mathrm{~m} / \mathrm{s}$.

Table 2. Specifications of wind turbine.

\begin{tabular}{cc}
\hline Type & H-Derrius \\
\hline Blade number & 3 \\
\hline Height of the rotor $(\mathrm{H})$ & $3.2 \mathrm{~m}$ \\
\hline Diameter of the rotor $(\mathrm{D})$ & $2.2 \mathrm{~m}$ \\
\hline Chord length $(\mathrm{C})$ & $0.3 \mathrm{~m}$ \\
\hline Dynamic viscosity $(\mu)$ & $1.83 \mathrm{e}-5 \mathrm{~N} \cdot \mathrm{s} / \mathrm{m}^{2}$ \\
\hline Air density $(\rho)$ & $1.225 \mathrm{~kg} / \mathrm{m}^{3}$ \\
\hline Cut-in speed $(\mathrm{V})$ & $3 \mathrm{~m} / \mathrm{s}$ \\
\hline Reynolds Number & 40,164 \\
\hline
\end{tabular}

To design a vertical axis wind turbine, a new type of airfoil called KA2, developed in the Kunsan national university, is used [27]. The shape of this airfoil is shown in Figure 6.

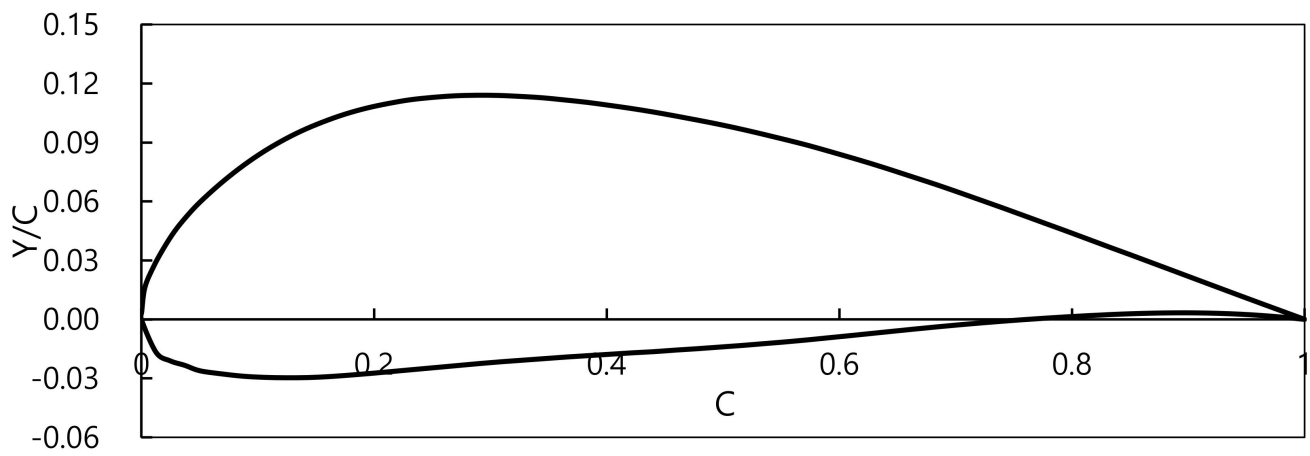

Figure 6. KA2 airfoil coordination.

The lift and drag coefficients of the KA2 are shown in Figure 7. The KA2 has a maximum lift coefficient of 1.4 and a maximum drag coefficient of 2.962, and a maximum thickness ratio of $14 \%$ is an asymmetric airfoil. 

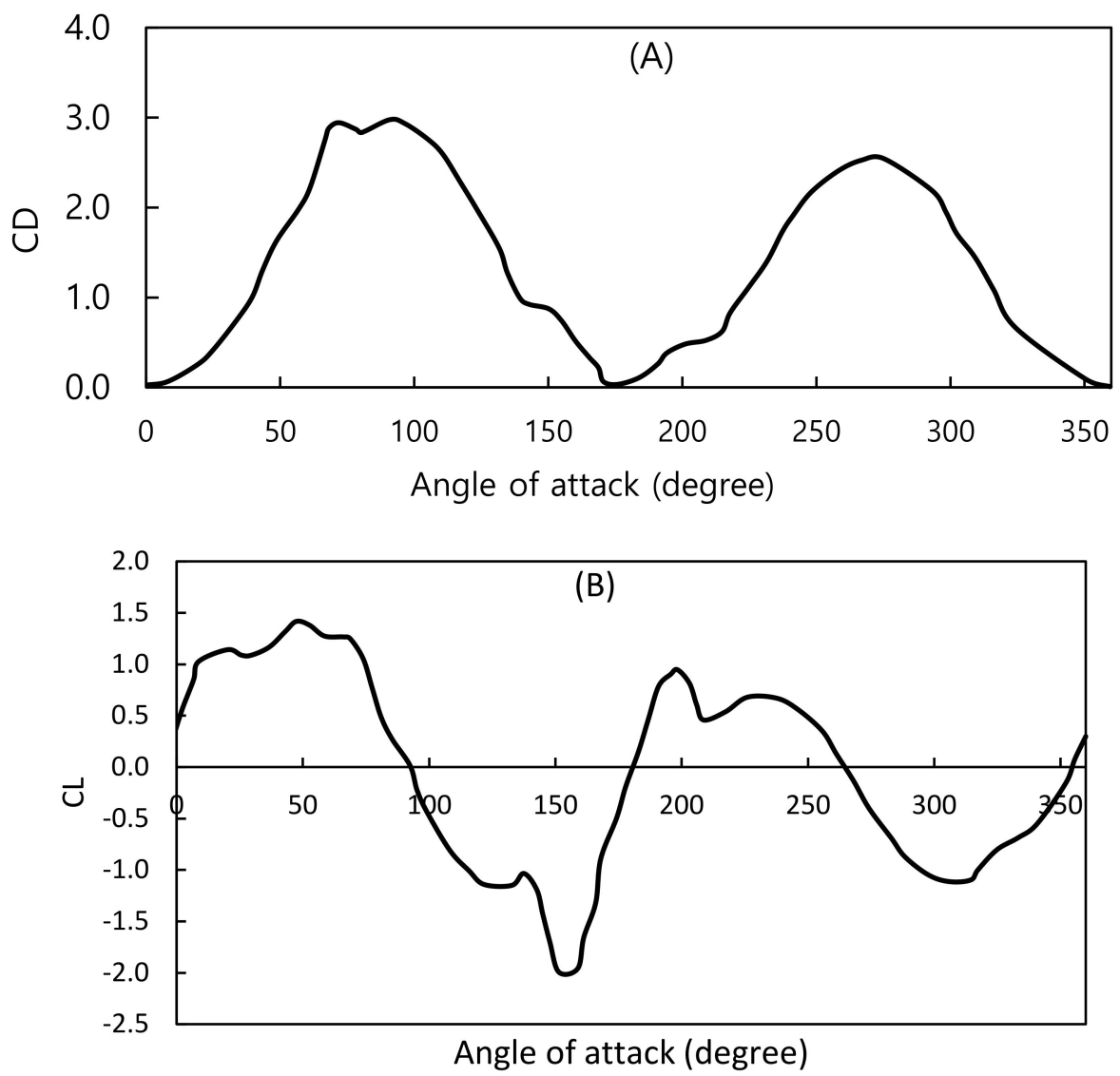

Figure 7. Aerodynamic characteristics of KA2 airfoil (A): Drag coefficient, (B): Lift coefficient at different angles of attacks.

\subsection{Blade Element Momentum Theory}

The principle of implementing BEM for the Darrius wind turbine is briefly explained by Tai [28]. After projecting the aerodynamic loads on blades (see Figure 8), the output power of the wind turbine will be calculated at different wind speeds regarding the flow chart in Figure 9 and Table 3.

Table 3. Equations used in the flowchart (Figure 9).

\begin{tabular}{ccc}
\hline Name & Equations & Number of Equations \\
\hline Induction factor & $a=1-\frac{U}{U_{\infty}}$ & $(5)$ \\
Angle of attack & $\alpha=\tan ^{-1}\left(\frac{U \sin \varnothing}{U \cos \varnothing+R \omega}\right)$ & $(6)$ \\
Relative velocity & $U_{R}=\frac{U \sin \varnothing}{\sin \alpha}$ & $(7)$ \\
Tangential coefficient & $C_{t}=C_{L} \sin \alpha-C_{D} \cos \alpha$ \\
Tangential force & $F_{t}=\frac{1}{2} C_{t} \rho h c U_{R^{2}}$ \\
Power & $p=F_{t} R \omega$ & $(10)$ \\
\hline
\end{tabular}




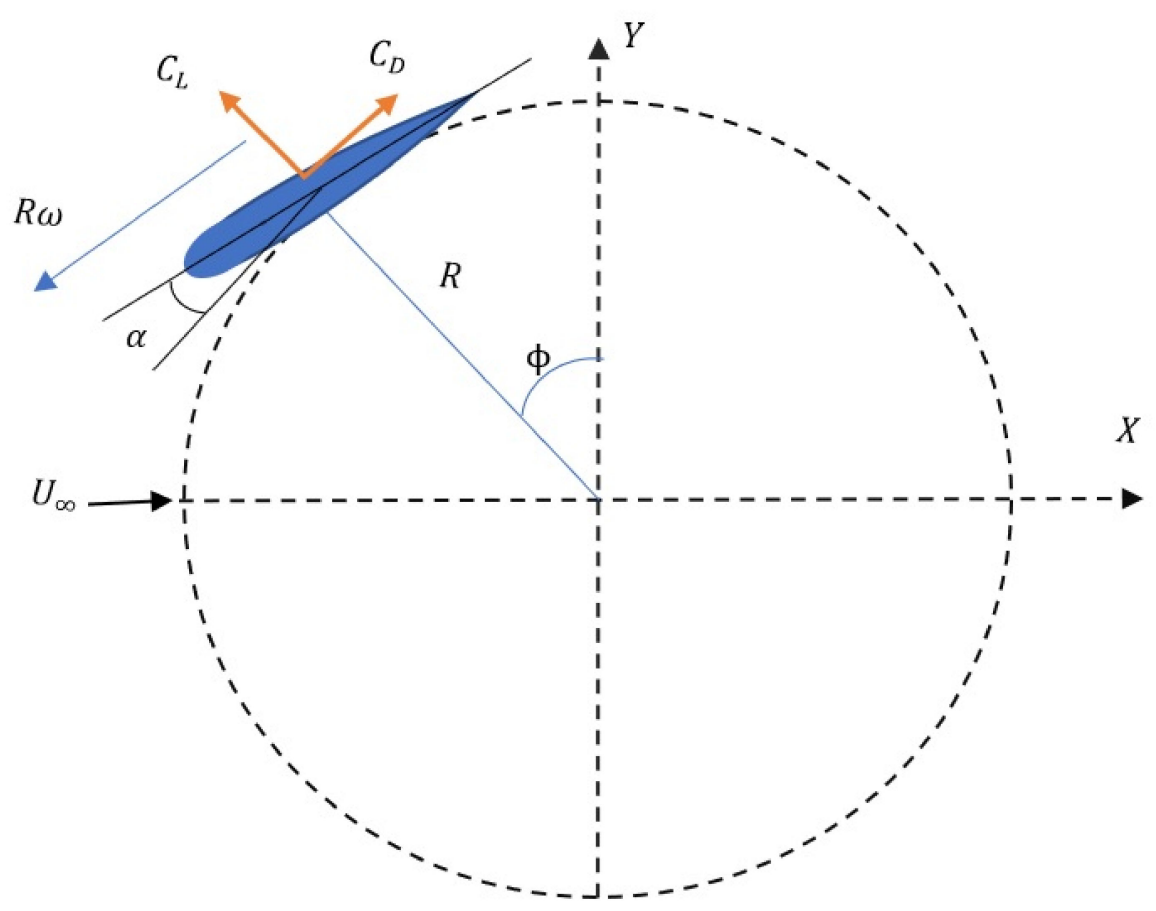

Figure 8. Aerodynamic load of Darrius wind turbine.

Briefly, calculating the wind turbine power performance, the following steps should be followed:

(1) At the first position $\left(\theta_{0}\right)$ : Assign a value of the local stream tube wind speed (U) and the corresponding induction factor, $a$ (Equation (5)), at the specified position.

(2) Calculate the angle of attack, $\alpha$ (Equation (6)), and relative velocity, $U_{R}$ (Equation (7)).

(3) Find out the values of $\mathrm{Ct}$ (Equation (8)) by applying the interpolation method with CL and CD.

(4) Calculate the values of tangential force, Ft (Equation (9)), and new induction factor, $\alpha_{i+1}$

(5) Compare the values of local induction factors. If the residual is equal to or less than 0.001 , then go on to the next step. Otherwise, replace the initial value of the induction factor, and go back to step 2.

(6) Repeat the loop until $\varnothing=360$

(7) Calculate the torque and output power. 


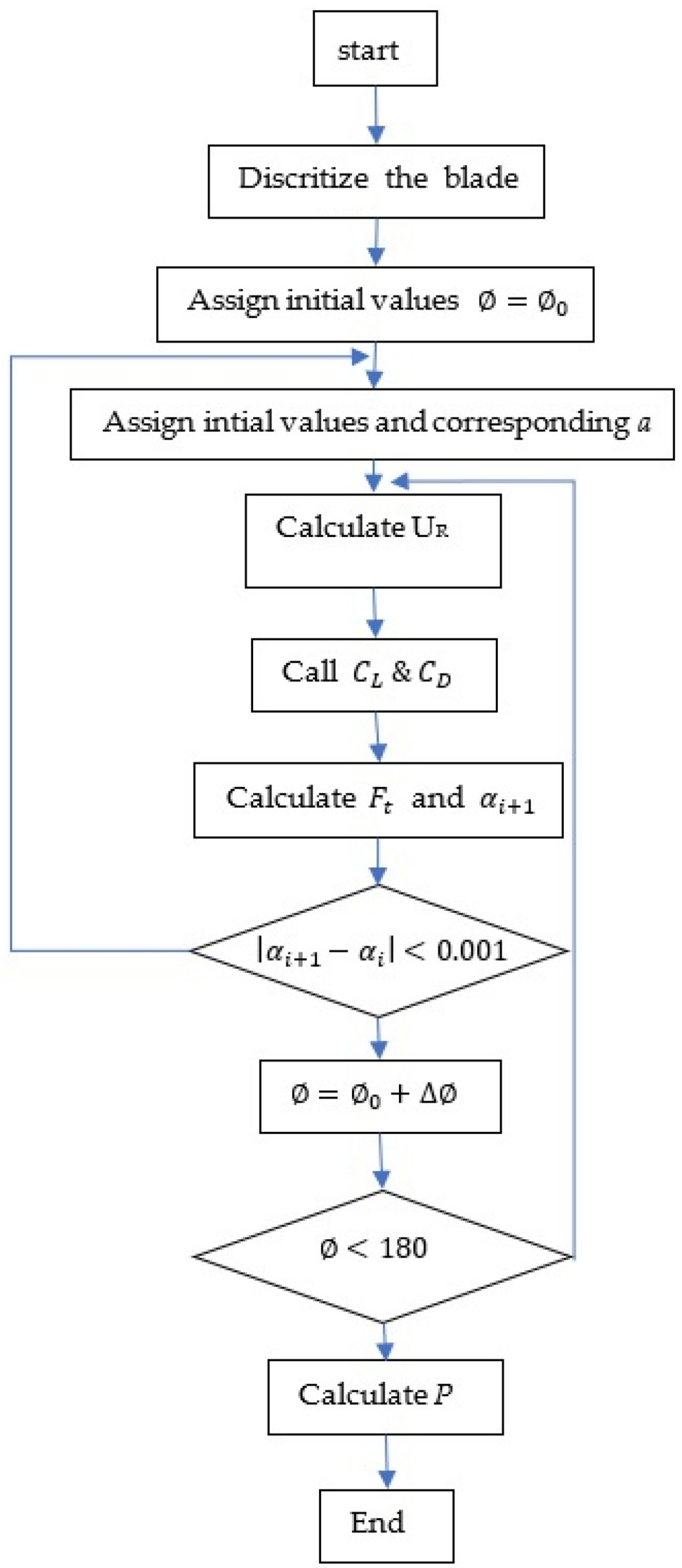

Figure 9. Flow chart used to run the BEM method. 


\section{Methodology}

In this paper, at first, four different PMECHs will be tested at different rotational speeds from $100 \mathrm{rpm}$ to $500 \mathrm{rpm}$ to measure torque and required power. The torque and rotational speed will be measured by torque and rpm sensors located between the altering current motor and the heat generator. In the second step, the measured data for all four case studies, which have different magnet numbers, poles, and gaps in both $\mathrm{Z}$ and $\theta$ directions between magnets will be compared together at various rotational speeds to show the effect of these variables on the heat generator's input torque.

Then, based on the rotational speed and torque measurements, the input power of the heat generators will be obtained. Since, in most of the studies, it was measured that the power coefficient of the eddy current heat generators can be more than $90 \%$ or equivalent [8], in this study, there is no discussion about the power coefficient of devices.

Finally, a vertical axis wind turbine that can meet the required power for each case will be designed. In this regard, we will compare the starting torque and power amount between each case and the wind turbine.

Previous studies showed that changing some parameters such as the air gap between the magnet and conductor, the use of different metals as a conductor, and conductor thickness change the output power. However, these parameters can change the size and final cost of the heat generator too. The main goals of this research are to study the effects of magnet arrangement, permanent magnet number, and pole number on the eddy currents heat generator's power at different rotational speeds. Studying these variables can help us to increase the productivity of the wind-heat generator system, while the size of the system remains fixed.

\section{Results and Discussions}

\subsection{Uncertainty}

The first step to improve the reliability of experimental results is the calculation of uncertainty. The uncertainties of the heat generator's input power of the PMECHs are calculated in Tables 4-7. The uncertainty of each case is important to answer the validation of the experimental precision measurement. Case 1 has the highest amount of uncertainty $(0.87 \%)$ among all. On the other hand, for cases 2,3 , and 4 , when the input torque increases, the uncertainty of the models declines.

Table 4. Relative uncertainty of case 1 in terms of output energy.

\begin{tabular}{|c|c|c|c|c|c|c|}
\hline Item & RPM & Factor & Measurement & Unit & Accuracy & $\begin{array}{c}\text { Relative } \\
\text { Uncertainty }\end{array}$ \\
\hline \multirow{10}{*}{ Case 1} & \multirow{2}{*}{100} & $\mathrm{~T}$ & 0.755 & $\mathrm{~N} \cdot \mathrm{m}$ & $0.87 \%$ & \multirow{2}{*}{$0.87 \%$} \\
\hline & & $\omega$ & 10.5 & $\mathrm{rad} / \mathrm{s}$ & $\pm 0.031 \mathrm{rad} / \mathrm{s}$ & \\
\hline & \multirow{2}{*}{200} & $\mathrm{~T}$ & 1.76 & $\mathrm{~N} \cdot \mathrm{m}$ & $0.87 \%$ & \multirow{2}{*}{$0.87 \%$} \\
\hline & & $\omega$ & 20.8 & $\mathrm{rad} / \mathrm{s}$ & $\pm 0.031 \mathrm{rad} / \mathrm{s}$ & \\
\hline & \multirow{2}{*}{300} & $\mathrm{~T}$ & 2.688 & $\mathrm{~N} \cdot \mathrm{m}$ & $0.87 \%$ & \multirow{2}{*}{$0.87 \%$} \\
\hline & & $\omega$ & 31.1 & $\mathrm{rad} / \mathrm{s}$ & $\pm 0.031 \mathrm{rad} / \mathrm{s}$ & \\
\hline & \multirow{2}{*}{400} & $\mathrm{~T}$ & 3.5 & $\mathrm{~N} \cdot \mathrm{m}$ & $0.87 \%$ & \multirow{2}{*}{$0.87 \%$} \\
\hline & & $\omega$ & 41.5 & $\mathrm{rad} / \mathrm{s}$ & $\pm 0.031 \mathrm{rad} / \mathrm{s}$ & \\
\hline & \multirow{2}{*}{500} & $\mathrm{~T}$ & 4.269 & $\mathrm{~N} \cdot \mathrm{m}$ & $0.87 \%$ & \multirow{2}{*}{$0.87 \%$} \\
\hline & & $\omega$ & 52.1 & $\mathrm{rad} / \mathrm{s}$ & $\pm 0.031 \mathrm{rad} / \mathrm{s}$ & \\
\hline
\end{tabular}


Table 5. Relative uncertainty of case 2 in terms of output energy.

\begin{tabular}{|c|c|c|c|c|c|c|}
\hline Item & RPM & Factor & Measurement & Unit & Accuracy & $\begin{array}{c}\text { Relative } \\
\text { Uncertainty }\end{array}$ \\
\hline \multirow{10}{*}{ Case 2} & \multirow{2}{*}{100} & $\mathrm{~T}$ & 9.99 & $\mathrm{~N} \cdot \mathrm{m}$ & $0.87 \%$ & \multirow{2}{*}{$0.87 \%$} \\
\hline & & $\omega$ & 10.6 & $\mathrm{rad} / \mathrm{s}$ & $\pm 0.031 \mathrm{rad} / \mathrm{s}$ & \\
\hline & \multirow{2}{*}{200} & $\mathrm{~T}$ & 17.17 & $\mathrm{~N} \cdot \mathrm{m}$ & $0.47 \%$ & \multirow{2}{*}{$0.47 \%$} \\
\hline & & $\omega$ & 20.8 & $\mathrm{rad} / \mathrm{s}$ & $\pm 0.031 \mathrm{rad} / \mathrm{s}$ & \\
\hline & \multirow{2}{*}{300} & $\mathrm{~T}$ & 21.46 & $\mathrm{~N} \cdot \mathrm{m}$ & $0.47 \%$ & \multirow{2}{*}{$0.47 \%$} \\
\hline & & $\omega$ & 31.6 & $\mathrm{rad} / \mathrm{s}$ & $\pm 0.031 \mathrm{rad} / \mathrm{s}$ & \\
\hline & \multirow{2}{*}{400} & $\mathrm{~T}$ & 24.13 & $\mathrm{~N} \cdot \mathrm{m}$ & $0.47 \%$ & \multirow{2}{*}{$0.47 \%$} \\
\hline & & $\omega$ & 41.6 & $\mathrm{rad} / \mathrm{s}$ & $\pm 0.031 \mathrm{rad} / \mathrm{s}$ & \\
\hline & \multirow{2}{*}{500} & $\mathrm{~T}$ & 25.93 & $\mathrm{~N} \cdot \mathrm{m}$ & $0.23 \%$ & \multirow{2}{*}{$0.23 \%$} \\
\hline & & $\omega$ & 51.8 & $\mathrm{rad} / \mathrm{s}$ & $\pm 0.031 \mathrm{rad} / \mathrm{s}$ & \\
\hline
\end{tabular}

Table 6. Relative uncertainty of case 3 in terms of output energy.

\begin{tabular}{|c|c|c|c|c|c|c|}
\hline Item & RPM & Factor & Measurement & Unit & Accuracy & $\begin{array}{c}\text { Relative } \\
\text { Uncertainty }\end{array}$ \\
\hline \multirow{10}{*}{ Case 3} & \multirow{2}{*}{100} & $\mathrm{~T}$ & 7.55 & $\mathrm{~N} \cdot \mathrm{m}$ & $0.87 \%$ & \multirow{2}{*}{$0.87 \%$} \\
\hline & & $\omega$ & 10.6 & $\mathrm{rad} / \mathrm{s}$ & $\pm 0.031 \mathrm{rad} / \mathrm{s}$ & \\
\hline & \multirow{2}{*}{200} & $\mathrm{~T}$ & 12.9 & $\mathrm{~N} \cdot \mathrm{m}$ & $0.87 \%$ & \multirow{2}{*}{$0.87 \%$} \\
\hline & & $\omega$ & 20.8 & $\mathrm{rad} / \mathrm{s}$ & $\pm 0.031 \mathrm{rad} / \mathrm{s}$ & \\
\hline & \multirow{2}{*}{300} & $\mathrm{~T}$ & 16.052 & $\mathrm{~N} \cdot \mathrm{m}$ & $0.47 \%$ & \multirow{2}{*}{$0.47 \%$} \\
\hline & & $\omega$ & 31.6 & $\mathrm{rad} / \mathrm{s}$ & $\pm 0.031 \mathrm{rad} / \mathrm{s}$ & \\
\hline & \multirow{2}{*}{400} & $\mathrm{~T}$ & 18.4 & $\mathrm{~N} \cdot \mathrm{m}$ & $0.47 \%$ & \multirow{2}{*}{$0.47 \%$} \\
\hline & & $\omega$ & 41.6 & $\mathrm{rad} / \mathrm{s}$ & $\pm 0.031 \mathrm{rad} / \mathrm{s}$ & \\
\hline & \multirow{2}{*}{500} & $\mathrm{~T}$ & 19.522 & $\mathrm{~N} \cdot \mathrm{m}$ & $0.47 \%$ & \multirow{2}{*}{$0.47 \%$} \\
\hline & & $\omega$ & 51.8 & $\mathrm{rad} / \mathrm{s}$ & $\pm 0.031 \mathrm{rad} / \mathrm{s}$ & \\
\hline
\end{tabular}

Table 7. Relative uncertainty of case 4 in terms of output energy.

\begin{tabular}{|c|c|c|c|c|c|c|}
\hline Item & RPM & Factor & Measurement & Unit & Accuracy & $\begin{array}{c}\text { Relative } \\
\text { Uncertainty }\end{array}$ \\
\hline \multirow{10}{*}{ Case 4} & \multirow{2}{*}{100} & $\mathrm{~T}$ & 11.672 & $\mathrm{~N} \cdot \mathrm{m}$ & $0.87 \%$ & \multirow{2}{*}{$0.87 \%$} \\
\hline & & $\omega$ & 10.55 & $\mathrm{rad} / \mathrm{s}$ & $\pm 0.031 \mathrm{rad} / \mathrm{s}$ & \\
\hline & \multirow{2}{*}{200} & $\mathrm{~T}$ & 20.58 & $\mathrm{~N} \cdot \mathrm{m}$ & $0.47 \%$ & \multirow{2}{*}{$0.47 \%$} \\
\hline & & $\omega$ & 21 & $\mathrm{rad} / \mathrm{s}$ & $\pm 0.031 \mathrm{rad} / \mathrm{s}$ & \\
\hline & \multirow{2}{*}{300} & $\mathrm{~T}$ & 26.69 & $\mathrm{~N} \cdot \mathrm{m}$ & $0.23 \%$ & \multirow{2}{*}{$0.23 \%$} \\
\hline & & $\omega$ & 31.9 & $\mathrm{rad} / \mathrm{s}$ & $\pm 0.031 \mathrm{rad} / \mathrm{s}$ & \\
\hline & \multirow{2}{*}{400} & $\mathrm{~T}$ & 30.958 & $\mathrm{~N} \cdot \mathrm{m}$ & $0.23 \%$ & \multirow{2}{*}{$0.23 \%$} \\
\hline & & $\omega$ & 41.9 & $\mathrm{rad} / \mathrm{s}$ & $\pm 0.031 \mathrm{rad} / \mathrm{s}$ & \\
\hline & \multirow{2}{*}{500} & $\mathrm{~T}$ & 33.457 & $\mathrm{~N} \cdot \mathrm{m}$ & $0.23 \%$ & \multirow{2}{*}{$0.23 \%$} \\
\hline & & $\omega$ & 51.4 & $\mathrm{rad} / \mathrm{s}$ & $\pm 0.031 \mathrm{rad} / \mathrm{s}$ & \\
\hline
\end{tabular}




\subsection{Heat Generator Measurement}

Figure 10 shows the torque measured at different rotational speeds for all four cases. Increasing steadily from 0.755 N.m at the rotational speed of $100 \mathrm{rpm}$ to 4.26 N.m at the rotational speed of $500 \mathrm{rpm}$, case 1 needs the lowest amount of torque to rotate in all rotational speeds, though it has the largest numbers of pole and permanent magnets than the other cases. On the other hand, surprisingly, by inserting just a $40 \mathrm{~mm}$ gap between magnets in the $\mathrm{Z}$ and $25 \mathrm{~mm}$ in the $\theta$ direction, the torque needed to rotate case 4 raised sharply from 11.672 N.m at the rotational speed of $100 \mathrm{rpm}$ to $33.457 \mathrm{~N} . \mathrm{m}$ at the rotational speed of $500 \mathrm{rpm}$. In cases 2 and 3, however, increasing the gap in the $\theta$ direction decreases the required torque compared to case 4 . Figure 11, meanwhile, shows the effect of the pole number on torque measurement at a rotational speed of $100 \mathrm{rpm}$. Increasing the pole numbers from 12 to 24 causes the torque growth, while in case 1 with 48 as the pole number on the rotor, we can see a sharp reduction in measured torque. One reason would be that when there is no gap between the magnet with the same pole direction, the magnetic field created by each magnet will close mainly between the adjacent magnets, not with the stator ring, resulting in poor input torque.

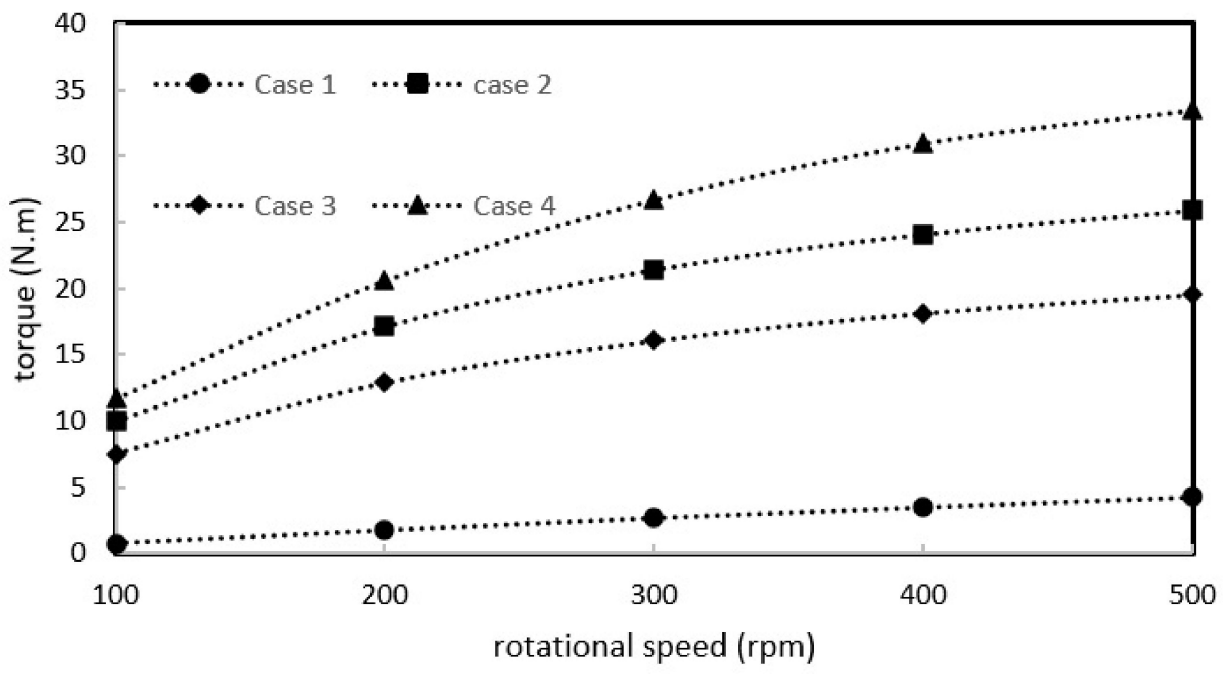

Figure 10. Torque measurements in different rotational speeds.

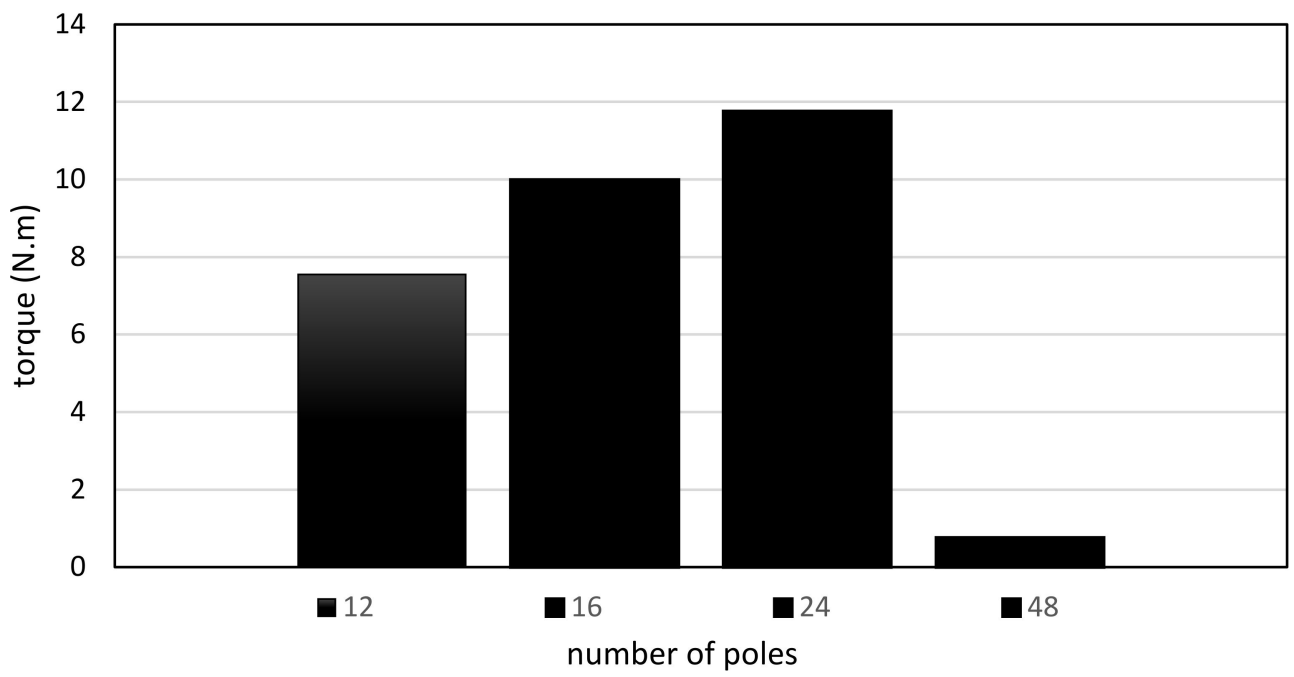

Figure 11. Torque changes vs. pole number at rotational speed of $100 \mathrm{rpm}$. 
The input torque per permanent magnet numbers for each case is measured to see the input torque changes regardless of each rotor's weight (see Figures 12 and 13). This measurement can be a good variable to show the torque per each magnet of PMECH, which can compare the power capacity of each magnet arrangement.

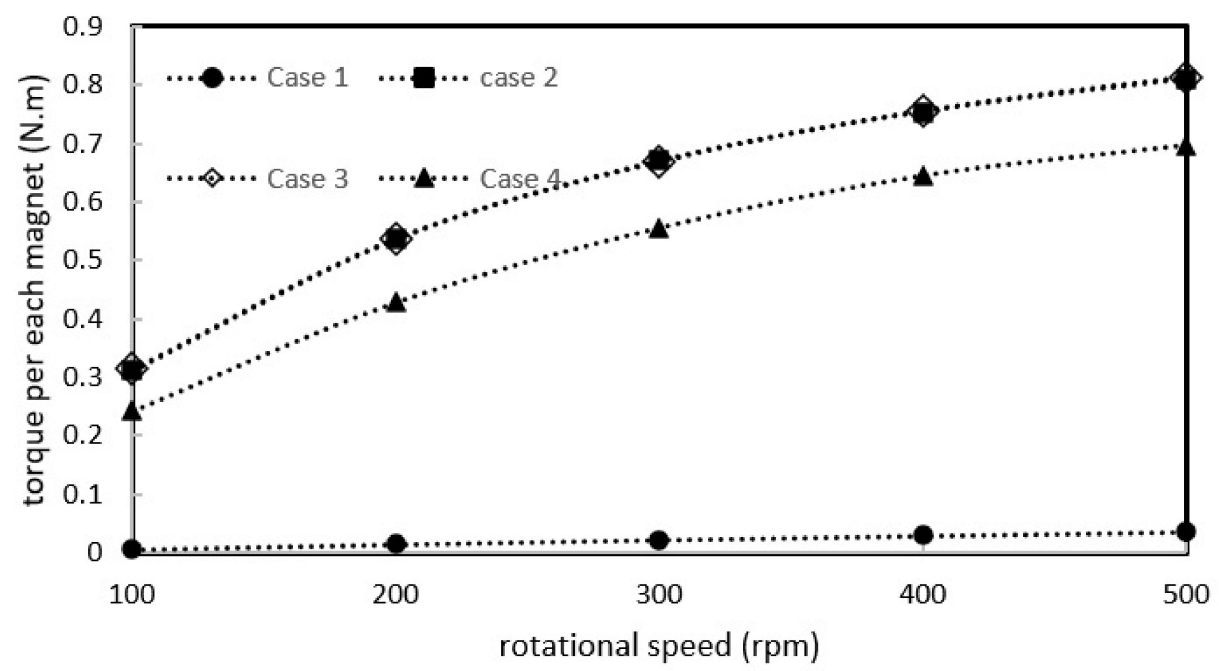

Figure 12. Torque per number of magnets at different rotational speeds.

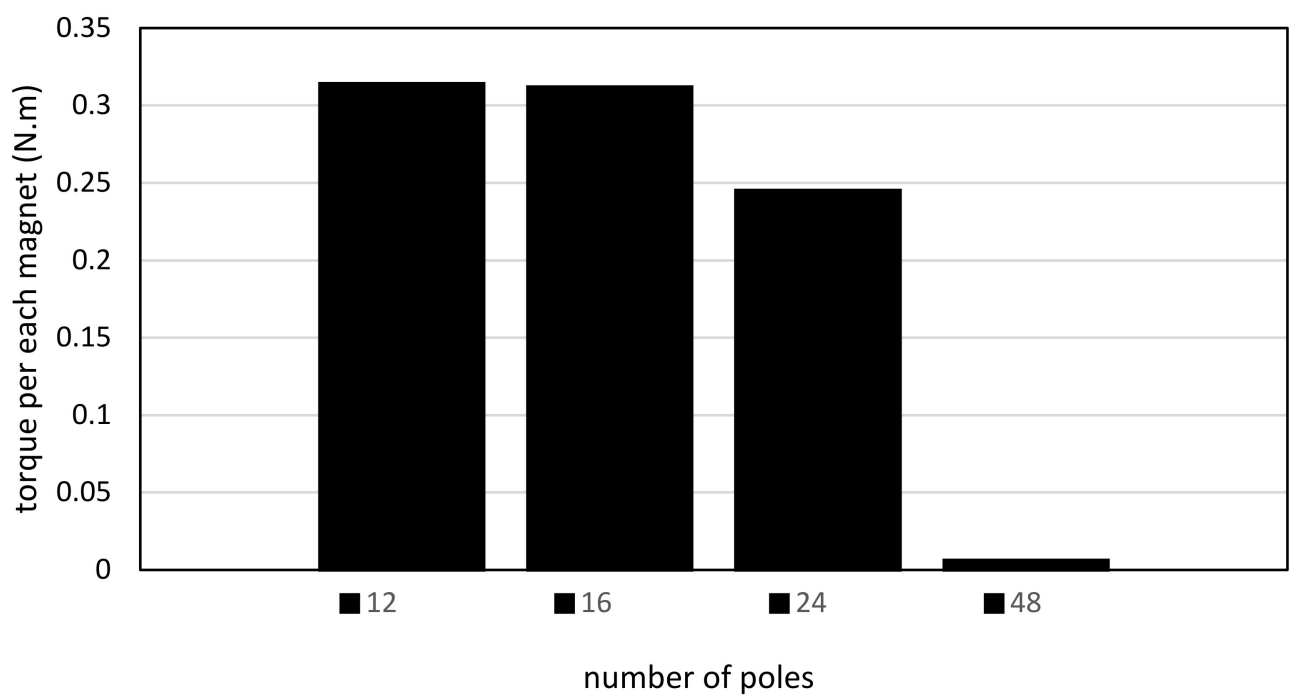

Figure 13. Torque per number of magnets vs. pole number at rotational speed of $100 \mathrm{rpm}$.

While case 3 needs the highest torque compared to the other cases, the needed torque per each magnet for this case is less than in cases 2 and 3. Surprisingly, there is no significant difference between cases 2 and 3 in terms of input torque per number of magnets. Thus, for cases 2 and 3 with pole numbers of 16 and 12, respectively, decreasing or increasing the gap between magnets in the $\theta$ direction does not have a significant effect on the input torque absorption per each magnet, and increasing the torque of the system is just because of the rising number of magnets and magnetization area of the rotor. On the other hand, in case 4 , it seems that widening the gap between magnets in the $\theta$ direction is needed to raise the torque capacity of magnets. In contrast, case 1 had the lowest torque per number of magnets, which means raising the number of magnets for this arrangement is not an effective parameter to induce more magnetic force on the PMECH. Therefore, changing the magnet arrangement is needed. 
The frequency of the heat generator will be calculated by following equation:

$$
f=\frac{P \cdot R P M}{120}
$$

where $f$ is frequency $(\mathrm{Hz})$, and $P$ is the pole number.

As for Figure 14, cases 2, 3, and 4 show a similar trend while frequency increases. However, in low frequency amounts, cases 2 and 3 need more input torque, but at high amounts of frequency more than $60 \mathrm{~Hz}$, case 3 needs more torque to rotate. In Figure 15, meanwhile, cases 2 and 3 see an exponential growth in needed torque per magnet while frequency increases. Compared to all cases, case 3 rises rapidly and reaches to the highest amount of 0.813 N.m for each magnet at a frequency of $50 \mathrm{~Hz}$.

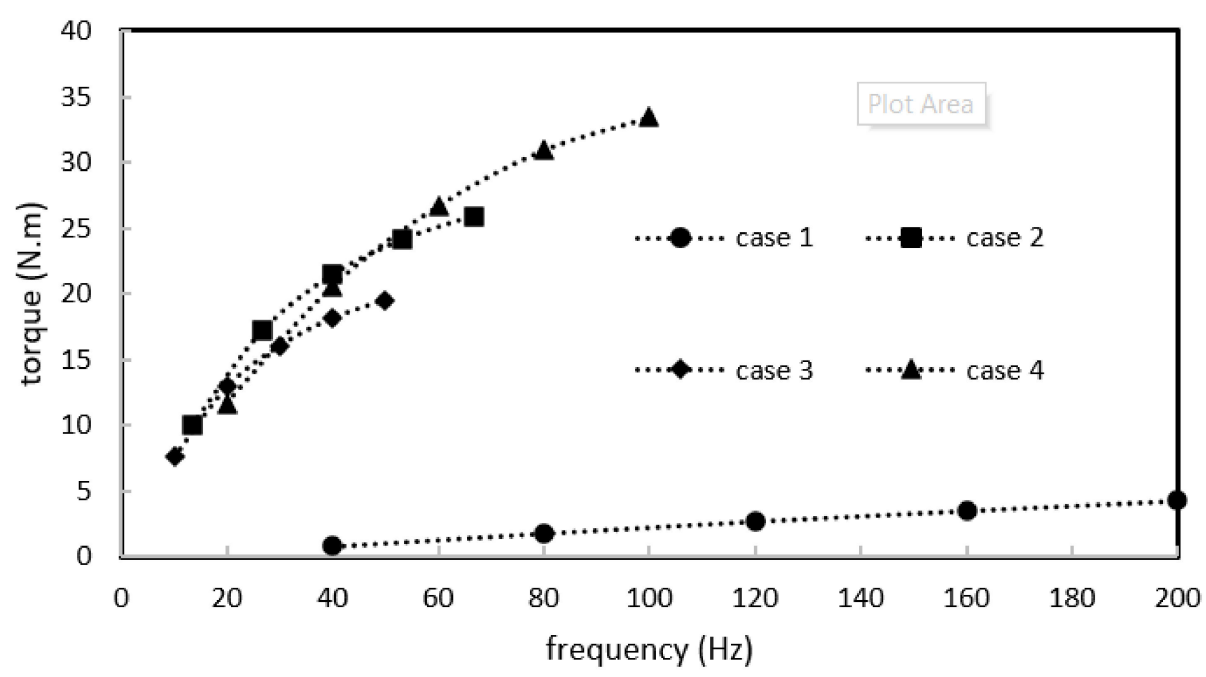

Figure 14. Torque changes at different frequencies.

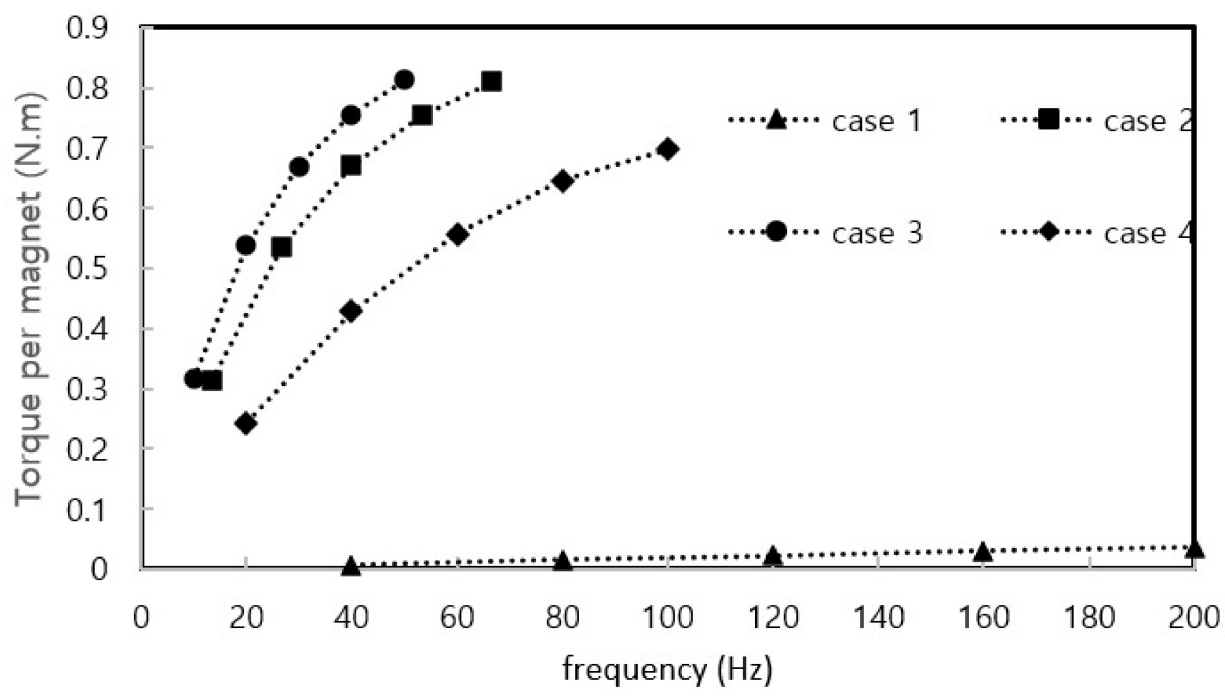

Figure 15. Torque per magnet changes at different frequencies.

\subsection{Wind Turbine}

After measuring the input torque of each PMECH, it is necessary to calculate the starting torque of the wind turbine as the first and most important part of system design.

Figure 16 shows the torque produced when the wind turbine begins to start at a wind speed of $3 \mathrm{~m} / \mathrm{s}$ at different azimuth angles of the wind rotor. The starting torque fluctuates somewhere between -0.11 N.m and 2 N.m. 


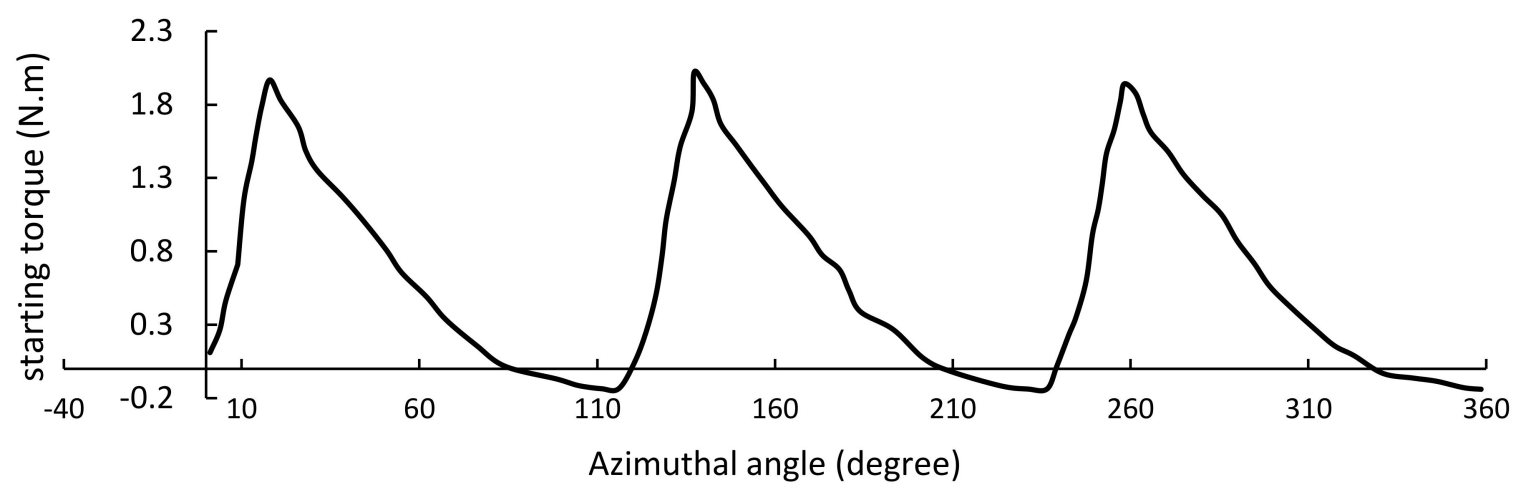

Figure 16. Starting torque of wind turbine with different pitch angles in the rotor plan.

In addition, the starting torque values of each PMECH is examined through the experiment. In Figure 17, the average torque produced by a wind turbine at a wind speed of $3 \mathrm{~m} / \mathrm{s}$ is calculated and compared with the required starting torque of all four cases. The wind turbine can meet the starting torque of each model in the wind speed of $3 \mathrm{~m} / \mathrm{s}$.

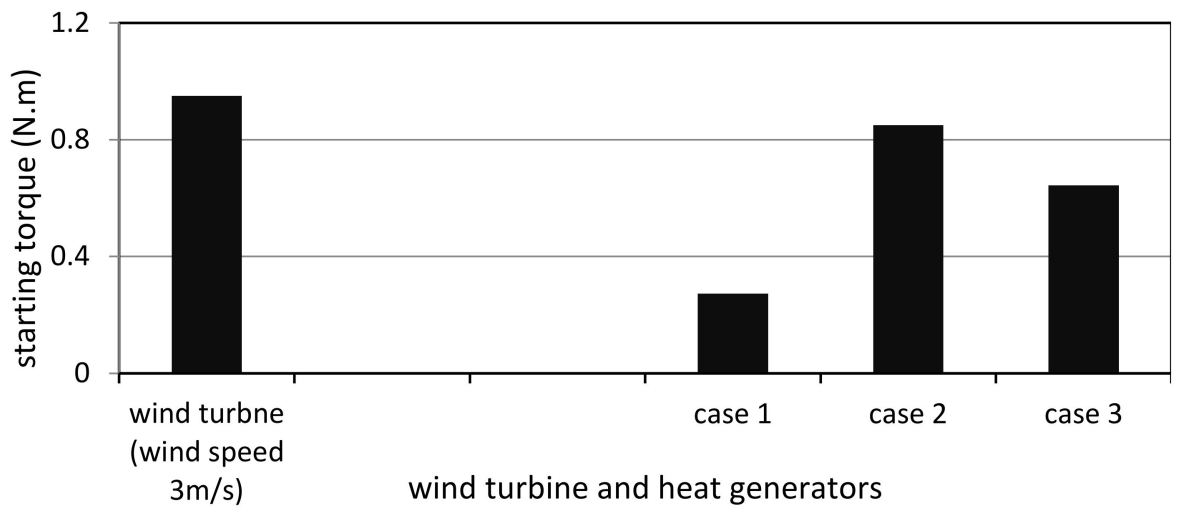

Figure 17. Comparison between torque needed to run PMECHs and wind turbine starting torque produced.

As shown in Figure 18, there is a comparison between the rated power of the wind turbine at three wind speeds of 4,5 , and $7 \mathrm{~m} / \mathrm{s}$ and the needed power to run the PMECHs at different rotational speeds. By increasing the wind speed from $4 \mathrm{~m} / \mathrm{s}$ to $7 \mathrm{~m} / \mathrm{s}$, the wind turbine can provide the needed power to run the heat generators at high rotational speeds. At a wind speed of $7 \mathrm{~m} / \mathrm{s}$, the system can generate $350 \mathrm{~W}$ power output for the heating demand.

Overall, several attempts have been conducted to increase the power capacity of PMECH based on the FEM methods, while there are not enough experimental studies focusing on how to increase the power performance. In simulation studies, it was reported that the air gap between magnets and the conductor, the conductor's material, and conductor thickness can change the power capacity $[14,15]$. However, changing these parameters will change the size and cost of the heat generator system. Previous studies showed that when the gap between magnets and the conductor is fixed, increasing the rotational speed will result in growth in the power input of PMECH [13], but it should be considered that due to some technical problems, the wind turbine cannot work at high rotational speeds. The pole number on the rotor is a key parameter to increase the input power. Studies show the optimum number of poles on their proposed system in a single rotational speed $[16,18]$. However, to increase the pole number on the rotor, more permanent magnets are needed to insert, leading to raising the total weight of the heat generator. Therefore, a portion of the wind turbine's torque will be used to rotate a heavy heat generator's rotor. In this 
study, we defined four different cases with different magnet arrangements and measured the amount of needed torque per magnet in each case. When the number of poles on the rotor increased, the magnetic fields produced by magnets need enough space to circulate freely. Thus, this idea will be more helpful to understand how arranging the permanent magnet on the rotor can change the PMECH power performance.

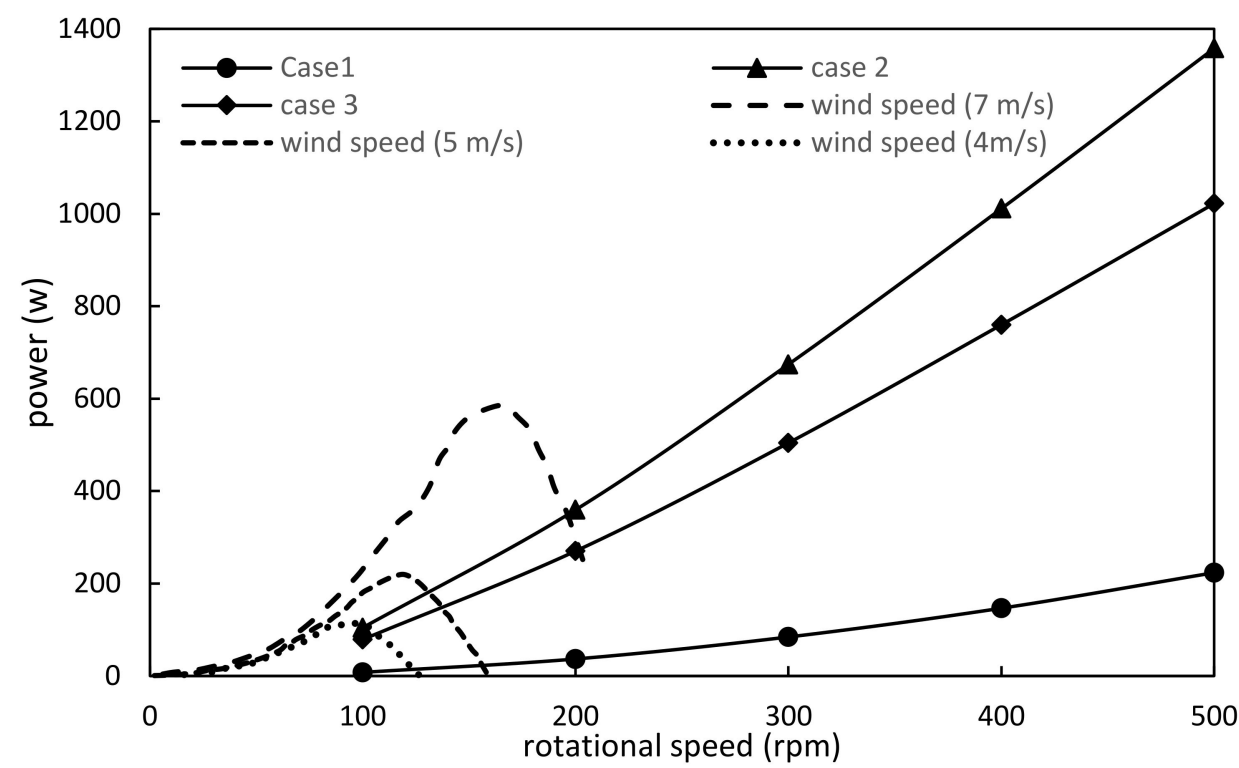

Figure 18. Comparison between power produced by wind turbine and needed power for each case at different rotational speeds.

\section{Conclusions}

In this paper, a permanent magnet eddy currents heater with different magnet areas was tested at different rotational speeds. Our results are summarized below:

- The effect of magnet arrangements on changing the torque is by far more significant than the number of magnets and magnet areas.

- Cases 2 and 3 have the same trend in terms of torque per magnet at different rotational speeds, which means that the inserted gap between magnets provides enough space to let magnetic fields circulate freely around the permanent magnets and induce the eddy current on the stator with the highest rate.

- Even though case 1 has the largest weight, it needs the lowest amount of torque to start the rotating, which means the momentum inertia of the rotor is not a more effective variable to raise the starting torque than the effect of eddy currents. Moreover, when there is no gap between the magnets, the magnetic field created by each magnet will close mainly between the permanent magnets, not with the stator ring, resulting in poor eddy current induction.

- While case 4 has the highest amount of torque in each rotational speed, the needed torque per magnet for this case is less than in cases 2 and 3 . Therefore, it can be concluded that the gap between magnets should be widened to let the magnetic fields circulate in bigger space.

- Increasing the pole number from 12 to 24 raises the input torque steadily, whereas a converse pattern occurs for torque per magnet when the pole number increases from 16 to 24. Therefore, it is recommended to find the optimal pole for a PMECH based on the needed torque per magnet.

- Regarding the wind turbine design, the highest power output occurs when coupling with case 2 at a wind speed of $7 \mathrm{~m} / \mathrm{s}$. 
Author Contributions: Conceptualization, A.K. and J.-H.L.; methodology, A.K. and S.K.; validation, A.K. and S.K.; formal analysis, A.K. and J.-H.L.; investigation, A.K. and S.K.; resources, J.-H.L.; data curation, D.-Y.J. and D.L.; writing—original draft preparation, A.K. and J.-H.L.; writing—review and editing, A.K.; J.-H.L.; S.K.; D.-Y.J. and D.L.; supervision, J.-H.L.; Project administration, J.H.L.; funding acquisition, J.-H.L. All authors have read and agreed to the published version of the manuscript.

Funding: This work was supported by the Korea Institute of Energy Technology Evaluation and Planning (KETEP) and the Ministry of Trade, Industry \& Energy (MOTIE) of the Republic of Korea (No. 20194030202300), and by the Ministry of Education (NRF-2017R1D1A3B06032145).

Data Availability Statement: The data in this study is available on requests from the corresponding author.

Conflicts of Interest: The authors declare no conflict of interest.

\section{Glossary}

\begin{tabular}{ll}
\hline Symbol & Variable \\
\hline $\mathrm{a}$ & Induction factor \\
$\mathrm{B}$ & Magnetic field strength (Tesla) \\
$\mathrm{C}$ & Chord $(\mathrm{m})$ \\
$\mathrm{CD}$ & Drag coefficient \\
$\mathrm{CL}$ & Lift coefficient \\
$\mathrm{Ct}$ & Tangential momentum \\
$\mathrm{E}$ & Electric field $(\mathrm{V} / \mathrm{m})$ \\
$F_{t}$ & Tangential force $(\mathrm{N})$ \\
$\mathrm{j}$ & Current density $\left(A / \mathrm{m}^{2}\right)$, \\
$\mathrm{P}$ & Power $(\mathrm{W})$ \\
$\mathrm{T}$ & Torque $(\mathrm{N} \cdot \mathrm{m})$ \\
$\mathrm{U}$ & Velocity $(\mathrm{m} / \mathrm{s})$ \\
$\alpha$ & Angle of attack $($ degree $)$ \\
$\rho$ & Density of aluminum $\left(\mathrm{kg} / \mathrm{m}^{3}\right)$ \\
$\varnothing$ & Azimuth angle $($ degree $)$ \\
$\rho$ & Resistivity of the stator $(\mathrm{Ohm}-\mathrm{m})$ ore density $\left(\mathrm{kg} / \mathrm{m}^{3}\right)$ \\
$\omega$ & Angular velocity of the rotor $(\mathrm{rpm})$ \\
\hline
\end{tabular}

\section{References}

1. Assad, M.E.H.; Sadeghzadeh, M.; Ahmadi, M.H.; Al-Shabi, M.; Albawab, M.; Anvari-Moghaddam, A.; Hani, E.B. Space cooling using geothermal single-effect water/lithium bromide absorption chiller. Energy Sci. Eng. 2021, 9, 1747-1760. [CrossRef]

2. Khanjari, A.; Mahmoodi, E.; Ahmadi, M.H. Energy and exergy analyzing of a wind turbine in free stream and wind tunnel in CFD domain based on actuator disc technique. Renew. Energy 2020, 160, 231-249. [CrossRef]

3. Javadi, M.A.; Ahmadi, M.H.; Khalaji, M. Exergetic, economic, and environmental analyses of combined cooling and power plants with parabolic solar collector. Environ. Prog. Sustain. Energy 2020, 39, e13322. [CrossRef]

4. Khanjari, A.; Sarreshtehdari, A.; Mahmoodi, E. Modeling of Energy and Exergy Efficiencies of a Wind Turbine Based on the Blade Element Momentum Theory Under Different Roughness Intensities. J. Energy Resour. Technol. 2016, 139, 022005. [CrossRef]

5. Pinilla, M.; Martinez, S. Optimal design of permanent-magnet direct-drive generator for wind energy considering the cost uncertainty in raw materials. Renew. Energy 2012, 41, 267-276. [CrossRef]

6. Shi, N.; Wei, M.; Zhang, L.; Hu, X.; Song, B. Design and research of cooling system for $2.5 \mathrm{MW}$ permanent magnet wind turbine. Renew. Energy 2021, 168, 97-106. [CrossRef]

7. Aliferov, A.I.; Vlasov, D.S.; Promzelev, V.A.; Morev, A.E.; Bikeev, R.A. Induction heating based on permanent magnets with magnetic field concentrators. In Proceedings of the International Conference "Actual Issues of Mechanical Engineering" 2017 (AIME 2017), Tomsk, Russia, 27-29 July 2017. [CrossRef]

8. Ye, L.; Liang, C.; Liu, Y.; Li, D.; Liu, Z. Performance analysis and test of a novel eddy-current braking \& heating system for electric bus. Energy Convers. Manag. 2019, 183, 440-449. [CrossRef]

9. Worley, P. Heating Water with Wind or Hydro Power: Direct Conversion of Mechanical Energy to Heat Using Eddy Currents; The Ohio State University: Columbus, OH, USA, 2015.

10. Kang, S.; Khanjari, A.; You, S.; Lee, J.-H. Comparison of different statistical methods used to estimate Weibull parameters for wind speed contribution in nearby an offshore site, Republic of Korea. Energy Rep. 2021, 7, 7358-7373. [CrossRef] 
11. Chakirov, R.; Vagapov, Y. Direct Conversion of Wind Energy into Heat Using Joule Machine. Int. Conf. Environ. Comput. Sci. 2011, $19,12-17$.

12. Sobor, I.O.N.; Rachier, V.; Chiciuc, A. Small Wind Energy System with Permanent Magnet Eddy Current Heater; IRTUM: Chisinau, Moldova, 2013.

13. Liu, X.H.; Chen, C.C.; Yu, H.D.; Wei, G.D.; De Tian, Z. The Study of the Heat Device in Wind-Magnetic Water Heater. Adv. Mater. Res. 2011, 201-203, 460-464. [CrossRef]

14. Fireteanu, V.; Nebi, O. Finite Element Electromagnetic 2D Model of an Eddy. ICATE 2008, 62-7.

15. Tudorache, T.; Popescu, M. FEM optimal design of wind energy-based heater. Acta Polytech Hung. 2009, 6, 55-70.

16. Tudorache, T.; Melcescu, L. Outer rotor eddy current heater for wind turbines. Renew. Energy Environ. Sustain. 2016, 1, 25. [CrossRef]

17. Dirba, I.; Kleperis, J. Practical Application of Eddy Currents Generated by Wind. IOP Conf. Series Mater. Sci. Eng. 2011, $23,012011$. [CrossRef]

18. Tudorache, T.; Melcescu, L.; Predescu, M. Analysis of a Permanent Magnet Eddy Current Heater Driven by a Wind Turbine. Adv. Electr. Comput. Eng. 2015, 15, 53-58. [CrossRef]

19. Yun, T. Experimental Study on the Efficiency Measurement of the Heat Transformation Device from Rotational Energy. Master Thesis, Kunsan National University, Gunsan, Korea, 2014.

20. Slemon, G.R. On the Design of High-Performance Surface-Mounted PM Motors. IEEE Trans. Ind. Appl. 1994, 30, 134-140. [CrossRef]

21. Sebastian, T.; Slemon, G. Transient torque and short circuit capabilities of variable speed permanent magnet motors. IEEE Trans. Magn. 1987, 23, 3619-3621. [CrossRef]

22. Home. Mysite 1. Available online: https://www.yymagnet.co.kr/ (accessed on 28 December 2020).

23. Semantic Scholar. On The Use of Eddy Current Brakes as Tunable, Fast Turn-on Viscous Dampers for Haptic Rendering. Available online: https:/ / www.semanticscholar.org/paper/On-The-Use-of-Eddy-Current-Brakes-as-Tunable\%2C-Fast-GoslineCampion/19802533a83b67f00c8f5805fccc95ec12eb7483 (accessed on 9 September 2021).

24. Vizimag Download-A Program to Allow the Very Fast Modeling of 2D Magnetic Structures, and the Visualization. Available online: https: / /vizimag.software.informer.com/ (accessed on 13 September 2021).

25. Guide: Assessing Experimental Uncertainty—Supplement to AIAA S-071A-1999 (AIAA G-045-2003); American Institute of Aeronautics and Astronautics, Inc.: Reston, VA, USA, 2003. [CrossRef]

26. QBlade. Available online: http:/ / www.q-blade.org/ (accessed on 1 April 2021).

27. US9664173B2-Tip Airfoil of Wind Turbine Blade-Google Patents. Available online: https://patents.google.com/patent/US96641 73B2/en?oq=us9664173b2 (accessed on 30 March 2021).

28. Burton, T.; Sharpe, D.; Jenkins, N.; Bossanyi, E. Wind Energy Handbook; John Wiley \& Sons: Chichester, UK, 2001. 